\title{
The clinicopathological and prognostic implications of tyrosine phosphatase SHP2 and ankyrin Hook1 gene expression in non- small cell lung cancer patients treated with gemcitabine plus platinum as first-line chemotherapy
}

\author{
Hongyu Yang ${ }^{1,2}$, Lingjuan $\mathrm{He}^{1}$, Yi Zhang ${ }^{1}$, Yinyan $\mathrm{Li}^{1}$, Xin Huang ${ }^{1}$, Ying $\mathrm{Li}^{1}$, Yan Lou ${ }^{1,2}$, Linrun Wang ${ }^{1}$ \\ ${ }^{1}$ Department of Pharmacy, ${ }^{2}$ Key Laboratory of Drug Clinical Research and Evaluation Technology of Zhejiang Province, The First Affiliated \\ Hospital, College of Medicine, Zhejiang University, Hangzhou, China \\ Contributions: (I) Conception and design: L Wang, H Yang; (II) Administrative support: Y Lou; (III) Provision of study materials or patients: H Yang, \\ L He, Y Zhang; (IV) Collection and assembly of data: H Yang, L He; (V) Data analysis and interpretation: Y Zhang, Y Li, X Huang; (VI) Manuscript \\ writing: All authors; (VII) Final approval of manuscript: All authors. \\ Correspondence to: Linrun Wang; Yan Lou. The First Affiliated Hospital, College of Medicine, Zhejiang University, 79 Qingchun Road, Hangzhou \\ 310000, China. Email: linrunw@zju.edu.cn; yanlou@zju.edu.cn.
}

Background: SHP2, a widely expressed phosphatase, which has been linked to the initiation, progression and prognosis of various malignancies. We previously identified a new SHP2 anchorage protein Hook1 in the alveolar II epithelial cells, and it is suggested that Hook1 is a novel endogenous suppressor molecule of SHP2 phosphatase activity. Nevertheless, few studies have been mentioned the clinicopathological and prognostic relevance of SHP2 and Hook1 expression in patients with non-small cell lung cancer (NSCLC).

Methods: A total of 61 patients with NSCLC receiving gemcitabine plus carboplatin chemotherapy were studied. Immunohistochemical staining was conducted to determine the protein expression of SHP2 and Hook1. The relationships between gene expression and clinical and pathological factors, as well as prognosis, were evaluated.

Results: A significant correlation was observed between the SHP2 and Hook1 expression, with a total expression rate of $71.4 \%$. The positive expression of Hook1 in adenocarcinoma and in stage IIIb-IV was higher than that in patients with squamous $(73.5 \%$ vs. $31.2 \%, \mathrm{P}=0.013)$ and $\mathrm{I}-\mathrm{IIIa}(75 \%$ vs. $48.8 \%, \mathrm{P}=0.05)$, suggesting that Hook1 might act as an indicator of NSCLC status. However, no significant correlation was observed between Hook1 expression and survival time $(\mathrm{P}>0.05)$. In contrast, patients with negative SHP2 expression had a higher survival rate (median overall survival 68 vs. 24 months, $\mathrm{P}=0.003$ ). Cox multivariate regression analysis showed that SHP2 was an independent indicator for overall survival $(\mathrm{P}=0.009)$.

Conclusions: The present study suggested that NSCLC patients with negative SHP2 expression could benefit from gemcitabine plus carboplatin chemotherapy, and further study is needed to confirm the prognostic value of SHP2 and Hook1.

Keywords: SHP2; Hook1; non-small cell lung cancer (NSCLC); chemotherapy; prognostic value

Submitted Feb 17, 2020. Accepted for publication Jul 17, 2020.

doi: $10.21037 /$ apm-20-430

View this article at: http://dx.doi.org/10.21037/apm-20-430 


\section{Introduction}

Non-small cell lung cancer (NSCLC), which accounts for approximately $85 \%$ of all lung cancers, is one of the most common human malignancies with a poor prognosis. Chemotherapy has been the major treatment strategy for most solid tumors including NSCLC. However, NSCLCs are relatively insensitive to chemotherapy compared to small cell carcinoma (1-3). Thus, it is important to screen for molecular markers that could be used to characterize NSCLC metastasis and effectively predict prognosis.

Reversible phosphorylation, the most widely used posttranslational modification, is an important chemical basis for cellular signal regulation (4-6). Reversible phosphorylation of signal proteins is mainly conducted by classes of kinases and phosphatases, which perform phosphorylation and dephosphorylation, respectively $(7,8)$. In recent years, a large number of studies have shown that the tyrosine kinase family plays an important role in the regulation of lung development, damage repair and cancer. Receptor tyrosine kinases (RTKs) have become an important target for targeted treatment of lung cancer $(6,9)$. Conversely, the tyrosine phosphatase family which carries out important dephosphorylation functions, is relatively less studied (8). Src homology region 2-containing protein tyrosine phosphatase 2 (SHP2) is a typical nonreceptor phosphatase member of the protein tyrosine phosphatase (PTPs) family (10-12). It has extensive physiological significance in embryonic development, stem cell maintenance, inflammatory damage and repair, tumor occurrence and metastasis. Its involvement in cell signal regulation showed obvious tissue specificity and timing characteristics (13-19). The SHP2 protein is mainly composed of two conserved $\mathrm{N}$ ends $\mathrm{SH} 2$ (N-SH2) and the $\mathrm{C}$ terminal catalytic subunit PTP domain (C-PTP). Under normal circumstances, the C-PTP binds with N-SH2 to induce a state of selfinhibition in SHP2 (auto-inhibition). Exogenous stimuli (such as growth factor, inflammatory factor, or cytokine) release C-PTP from N-SH2 and enhance the phosphatase activity of activated SHP2 (active state). In recent years, the function of signal anchored proteins (docking proteins) has been widely studied in regulating protein phosphorylation. The anchored protein is also called a scaffolding protein or adaptor protein, which usually do not have enzymecatalyzed active groups. However, the signalosome complex regulates the signal specificity and accuracy by the direct interaction with the key kinase and phosphatase in the domain modified by phosphorylation (20-22).

We have previously identified a new SHP2 anchorage protein, Hook microtubule tethering protein 1 (Hook1), in the alveolar II epithelial cells by the yeast two-hybrid system. In vitro biochemical studies showed that Hook1 directly interacted with the PTP catalytic center of SHP2 in the self-inhibition state (23). It has been suggested that Hook1 is a novel endogenous suppressor molecule of SHP2 phosphatase activity that can stabilize a self-inhibited state of SHP2 under normal conditions $(23,24)$. Additional studies have confirmed the role of Hook1-TGF $\beta / \mathrm{Smad}$ signalling in the negative regulation of SHP2. However, the function of the Hook1 protein is still poorly understood. It is worth noting that the $\mathrm{N}$ segment of Hook1 has a cytoskeletal protein binding site, which is only known to be related to cell migration and intracellular vesicle transport $(25,26)$. Nevertheless, few studies have reported the clinicopathological and prognostic relevance of SHP2 and Hook1 expression in patients with non-small-cell lung cancer (NSCLC). Therefore, we conducted a retrospective study to determine the prognostic significance of tyrosine phosphatase SHP2 and ankyrin Hook1 in NSCLC.

We present the following article in accordance with the REMARK reporting checklist (available at http://dx.doi. org/10.21037/apm-20-430).

\section{Methods}

\section{Study participants}

A total of 101 NSCLC patients who underwent radical surgery in our hospital from January 2008 to December 2012 were selected. Sixty-one patients of them were confirmed by histopathology to receive gemcitabine plus platinum chemotherapy in different stages. All tumor specimens of patients who underwent pathological diagnosis were collected. The median follow-up duration for all patients was 30 months (range, $3-115$ months), and the last follow-up visit was February 28, 2017. The study was conducted in accordance with the Declaration of Helsinki (as revised in 2013). The study was approved by the Research Ethics Committee of the First Affiliated Hospital, School of Medicine, Zhejiang University (2016125) and informed consent was taken from all the patients.

Every patient received standard first-line chemotherapy: gemcitabine $1,200 \mathrm{mg} / \mathrm{m}^{2}$ on days 1 and 8 and carboplatin AUC 5 on day 1 (21 days per cycle). The platinum-based doublet chemotherapy treatment was repeated every 3 weeks for a maximum of 6 cycles. Progression-free survival (PFS) was calculated from the date of chemotherapy to progressive disease, which was assessed by chest X-ray and computed 
Table 1 Characteristics of patients included in the study

\begin{tabular}{|c|c|c|}
\hline Characteristic & Number & Percent (\%) \\
\hline \multicolumn{3}{|l|}{ Median age } \\
\hline$<60$ & 31 & 50.8 \\
\hline$\geq 60$ & 30 & 49.2 \\
\hline \multicolumn{3}{|l|}{ Gender } \\
\hline Female & 45 & 73.8 \\
\hline Male & 16 & 26.2 \\
\hline \multicolumn{3}{|l|}{ Smoking status } \\
\hline Yes & 36 & 59.0 \\
\hline No & 25 & 41.0 \\
\hline \multicolumn{3}{|l|}{ Performance stage } \\
\hline 0 & 44 & 72.1 \\
\hline 1 and 2 & 17 & 27.9 \\
\hline \multicolumn{3}{|l|}{ Histology } \\
\hline Squamous & 16 & 26.2 \\
\hline Adenocarcinoma & 34 & 55.7 \\
\hline Mixed NSCLC & 11 & 18.0 \\
\hline \multicolumn{3}{|l|}{ Stage } \\
\hline I-IIIa & 41 & 67.2 \\
\hline IIlb-IV & 20 & 32.8 \\
\hline
\end{tabular}

NSCLC, non-small cell lung cancer

tomography imaging. Overall survival (OS) was calculated from the start date of chemotherapy to the date of death or last clinical follow-up.

\section{Immunobistochemistry}

Tissue sections were deparaffinized and rehydrated through xylene and graded ethanol, respectively. Slides were rinsed in $\mathrm{dH}_{2} \mathrm{O}$ and then subjected to antigen retrieval in $10 \mathrm{mM}$ citrate buffer, $\mathrm{pH} 6.0$ by microwave oven heating for $20 \mathrm{~min}$ and cooling for $30 \mathrm{~min}$ at room temperature. Endogenous peroxidase activity was quenched in $0.3 \% \mathrm{H}_{2} \mathrm{O}_{2}$ for $20 \mathrm{~min}$ and then washed in PBS. Then slides were incubated with the primary antibody SHP2 (Abcam, ab32083) or Hook1 antibody (Abcam, ab151756) at a 1:100 dilution overnight at 4 ${ }^{\circ} \mathrm{C}$. After washing with PBS, the bound primary antibody was detected by a ready-to-use secondary antibody kit (Zhongshan Goldenbridge Biotech, Beijing, China) and the chromogenic substrate 3, 3-diaminobenzidine tetrahydrochloride (DAB).
The specimens were counterstained with haematoxylin, mounted and examined by light microscopy (Olympus BX50, Japan). SHP2 and Hook1 protein expression was divided into two groups according to the differential staining grades in the tumor cell nuclei or cytoplasm. The grading system was as follows: if immunoreactivity was noted in $<10 \%$ of tumor cells, it was defined as negative; if the immunoreactivity was $10 \%$ or more of the tumor cells, it was defined as positive.

\section{Statistical analysis}

All statistical analyses were carried out using SPSS software (Version 13.0; SPSS Inc., Chicago, IL, USA). Continuous variables are expressed as the mean and $\mathrm{SD}$, and categorical variables are expressed as percentages. Chi-square tests were calculated to assess the correlation between SHP2 and Hook1 protein expression and clinical characteristics of NSCLC. Kaplan-Meier survival curves and the log-rank test were used to analyse univariate distributions for survival. Cox proportional hazards regression was conducted to assess the effects of SHP2 and Hook1 protein expression on PFS and OS of NSCLC, with results expressed as hazard ratio (HR) and its $95 \%$ confidence interval (CI). Statistical significance was set at $\mathrm{P}=0.05$.

\section{Results}

\section{Patient characteristics}

A total of 61 patients with histologically confirmed NSCLC at our hospital admitted between January 2008 and December 2012 were included. There were 16 males and 45 females with ages ranging from 33 to 76 years (median age 60 years). Among 61 NSCLC patients, 16 cases were squamous cell carcinoma, 34 cases were adenocarcinoma, and 11 cases were mixed NSCLC. Histopathology confirmed that 41 cases were at the stage of I-IIIa and 20 cases were at IIIb-IV. Three patients received adjuvant chemotherapy and radiotherapy after the operation, and 1 patient received adjuvant chemotherapy after receiving cellular immunotherapy. The median follow-up time was 30 months (3-115 months). The last follow-up time was February 2017. Fifty-five patients had been developed progressive disease (PD), 45 patients died and 16 patients survived. The median OS of all patients was 30 months (ranging from 3 to 115 months), and the median PFS was 12 months (ranging from 1 to 77 months). The baseline characteristics of the 61 patients are shown in Table 1 . 

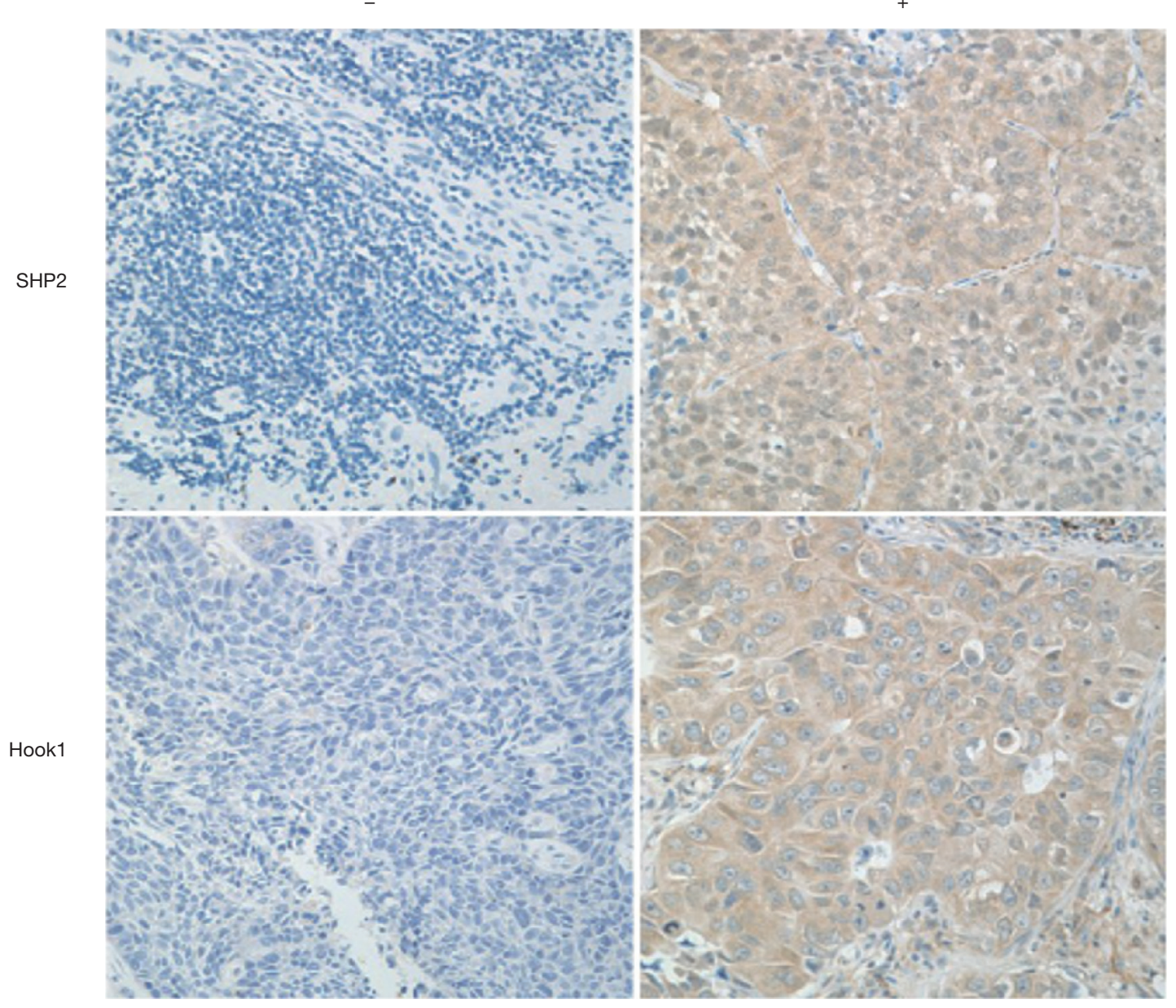

Figure 1 Photograph of tissue section in immunostained for SHP2 cytoplasm nuclear and Hook1 nuclear $(\times 200)$. SHP2, Src homology region 2-containing protein tyrosine phosphatase 2 .

Table 2 Correlation between SHP2 and Hook1 protein expression

\begin{tabular}{cccccc}
\hline & \multirow{2}{*}{ Number } & \multicolumn{2}{c}{ SHP2 } & P value & Coefficient \\
\cline { 3 - 5 } & & + & - & & 0.046 \\
\hline Hook1 & & & & & 0.256 \\
+ & 35 & 25 & 10 & & \\
- & 26 & 12 & 14 & & \\
Total & & 37 & 24 & & \\
\hline
\end{tabular}

SHP2, Src homology region 2-containing protein tyrosine phosphatase 2.

\section{SHP2 and Hook1 protein expression in NSCLC tumor tissues and their disease correlation}

We performed a correlation study on SHP2 and Hook1 protein expression using immunohistochemical (IHC) staining of tumor tissues from 61 NSCLC patients (Figure 1). In tumor tissue specimens, the positive expression rates of SHP2 and Hook1 proteins were $60.7 \%$ and $57.4 \%$, respectively. Among the 35 patients with positive Hook1 expression, 25 patients also had positive SHP2 expression, with a SHP2 and Hook1 positive expression rate of $71.4 \%$. A significant correlation between the positive expression of SHP2 and the positive expression of Hook1 was observed $(\mathrm{P}=0.046, \mathrm{r}=0.256$, Table 2).

Among the 61 cases of NSCLC, the positive rate of Hook1 protein expression differed in different pathological types (histology). Adenocarcinoma correlated with higher Hook1 expression than squamous cell carcinoma (positive rate $73.5 \%$ vs. $31.2 \%, \mathrm{P}=0.013$ ). Clinical stages (stage) IIIbIV have higher Hook1 expression than stage I-IIIa (positive rate $75 \%$ vs. $48.8 \%, \mathrm{P}=0.05$ ). 
Table 3 Relationship between SHP2/Hook1 expression and clinical characteristics

\begin{tabular}{|c|c|c|c|c|c|c|c|c|c|}
\hline Characteristic & $\mathrm{n}$ & \multicolumn{4}{|c|}{ Hook1 } & \multicolumn{4}{|c|}{ SHP2 } \\
\hline \multicolumn{10}{|l|}{ Median age } \\
\hline$<60$ & 31 & 14 & 17 & 0.166 & 0.684 & 15 & 16 & 2.16 & 0.142 \\
\hline$\geq 60$ & 30 & 12 & 18 & & & 9 & 21 & & \\
\hline Female & 45 & 21 & 24 & 1.147 & 0.284 & 15 & 30 & 2.597 & 0.107 \\
\hline Male & 16 & 5 & 11 & & & 9 & 7 & & \\
\hline \multicolumn{10}{|l|}{ Smoking status } \\
\hline Yes & 36 & 18 & 18 & 1.955 & 0.162 & 11 & 25 & 2.843 & 0.092 \\
\hline 0 & 44 & 19 & 25 & 0.02 & 0.887 & 19 & 25 & 0.974 & 0.324 \\
\hline 1 and 2 & 17 & 7 & 10 & & & 5 & 12 & & \\
\hline \multicolumn{10}{|l|}{ Histology } \\
\hline Squamous & 16 & 11 & 5 & 8.733 & 0.013 & 7 & 9 & 0.536 & 0.765 \\
\hline Adenocarcinoma & 34 & 9 & 25 & & & 12 & 22 & & \\
\hline Mixed NSCLC & 11 & 6 & 5 & & & 5 & 6 & & \\
\hline \multicolumn{10}{|l|}{ Stage } \\
\hline I-IIIa & 41 & 21 & 20 & 3.779 & 0.050 & 17 & 24 & 0.235 & 0.628 \\
\hline
\end{tabular}

SHP2, Src homology region 2-containing protein tyrosine phosphatase 2; NSCLC, non-small cell lung cancer.

There was no significant difference in age, smoking status or PS score (score 0 and scores ranging from 1 to 2$)(\mathrm{P}>0.05)$. These results show no significant correlation between SHP2 protein expression and clinical characteristics, including patient age, gender, smoking status, PS score, tissue morphologies, and clinical tumor stages $(\mathrm{P}>0.05)$. See Table 3.

\section{The correlation of SHP2 and Hook1 protein expression with clinical outcomes in NSCLC}

Cox proportional hazards regression analysis was conducted to assess the effects of SHP2 and Hook1 protein expression on progression-free survival (PFS) and overall survival (OS) of NSCLC patients. The survival rate of patients with negative SHP2 protein expression was higher than that of patients with positive SHP2 protein expression (median overall survival 68 vs. 24 months, $\mathrm{P}=0.003$, Figure $2 A$ ).
There was no significant correlation between the expression of Hook 1 and the survival time of patients $(\mathrm{P}>0.05$, Figure $2 B$ ). However, the survival rate in patients with negative expression of both SHP2 and Hook1 was higher than that in patients with positive expression of either SHP2 or Hook1 (68 versus 25 months, $\mathrm{P}=0.058$, Figure $2 C$ ), indicating a difference and impact on NSCLC patient survival. Cox multivariate regression analysis showed that SHP2 expression in tumor tissue [hazard ratio (HR): 4.520, 95\% CI: $1.470-14.021$, $\mathrm{P}=0.009]$ was an independent indicator for overall survival. No significant correlation between the protein expression of SHP2 or Hook1 and NSCLC disease progression was observed ( $\mathrm{P}>0.05)$. See Figure 2, Table 4 and Table 5.

\section{The effect of Hook1 protein expression on the OS and PFS of SHP2 positive patients}

Hook1 is not only the anchoring protein for SHP2, but 

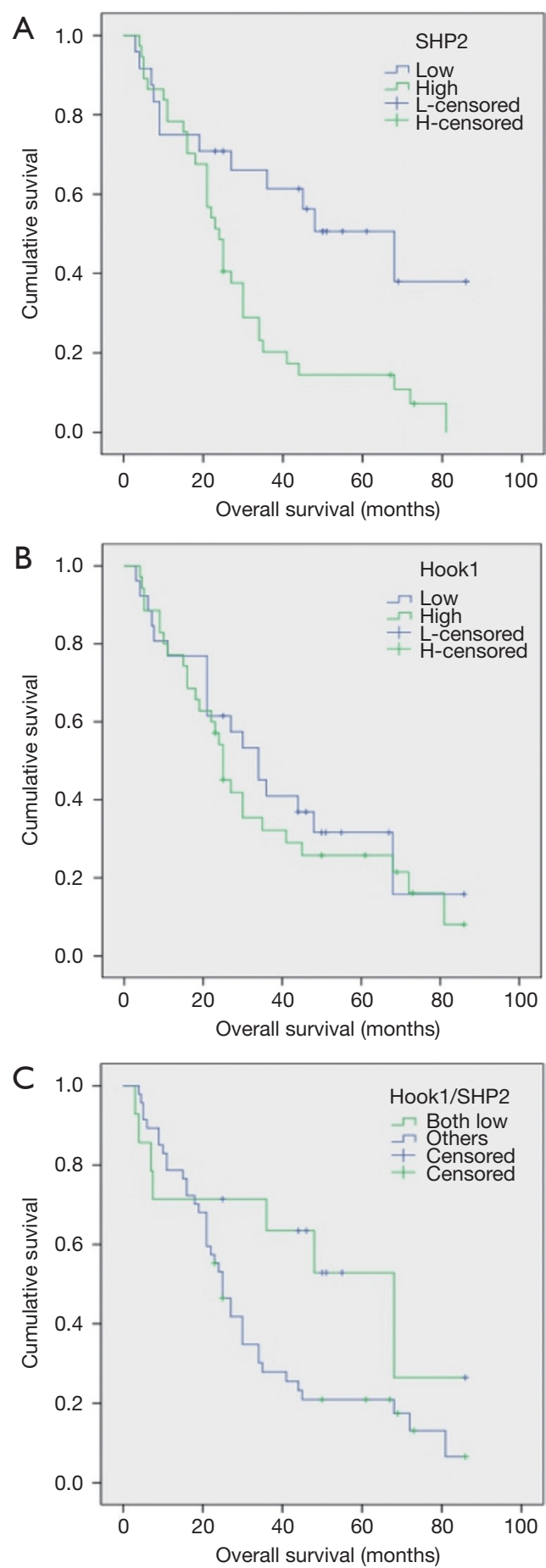

Figure 2 Survival analysis of SHP2 and Hook1 expression in patients with NSCLC. (A) Patients with negative SHP2 expression had a higher survival rate $(\mathrm{P}=0.003)$; (B) No difference was found between Hook1 expression and survival time $(\mathrm{P}>0.05)$; (C) The survival rate in patients with negative expression of both SHP2 and Hook1 was higher than that in patients with positive expression of either SHP2 or Hook1 (68 versus 25 months, $\mathrm{P}=0.058$ ). SHP2, Src homology region 2-containing protein tyrosine phosphatase 2. also affects the localization of SHP2 in cells and inhibits the catalytic activity of SHP2. We further analysed the effect of Hook1 expression on OS and PFS in SHP2 positive patients. Table 6 shows that there was no significant correlation between Hook1 expression level and OS and PFS in SHP2 positive patients $(\mathrm{P}>0.05)$.

\section{Discussion}

SHP2 is the only known proto-oncoprotein among many phosphatase molecules of the protein tyrosine phosphatase (PTP) family. The expression of SHP2 is increased or the coding gene is mutated in many tumor tissues (27). Recent studies suggested that SHP2 acted as a mediator for the regulation of motility in cancer cells through several signalling cascades $(18,28,29)$. Moreover, it was found that SHP2 was highly expressed in lung cancer and was related to lymph node metastasis, which suggests that enhanced SHP2 activity can accelerate tumor metastasis (30). Another study found that the SHP2 E76V mutation was detected in lung adenocarcinoma specimens, but not in normal lung tissue. Transgenic mice overexpressing the SHP2E76K mutation showed enhanced activation of ERK and Src in lung tissue, which eventually developed into lung adenocarcinoma (30). These results indicate that the active tyrosine phosphatase SHP2 produced by the active mutation has a strong carcinogenic effect. Recently, researchers have also found that in EGFR-L858R transgenic lung adenocarcinoma mice, the expression of SHP2 inactivated mutants can inhibit the occurrence of lung cancer in mice (31). These studies suggest that high expression or active mutation of SHP2 promotes the proliferation, invasion and metastasis of lung cancer cells $(31,32)$.

Hook1 is known as an anchoring protein that can bind to SHP2 at both the C-PTP and N-SH2 domains. This molecular interaction between SHP2 and Hook1 suggests that Hook1 may be involved in the maintenance of SHP2 self-inhibition, which is achieved through the interaction between the N-SH2 domain and the C-PTP domain. The temporal and spatial regulation of its intracellular catalytic activity of SHP2 is determined by the anchored protein bound to it. More importantly, in the epithelial to mesenchymal (EMT) process induced by TGF beta 1, the expression of Hook1 protein is downregulated, and SHP2 is easily activated (23). Under the stimulation of silencing Hookl protein and EGF, the activity of SHP2 increased significantly. Hook1 regulates SHP2 enzyme activity, thereby affecting the progression and prognosis of NSCLC. 
Table 4 Correlation between the OS and the expressions of SHP2 or/and Hook1 in NSCLC patients

\begin{tabular}{|c|c|c|c|c|c|c|}
\hline & $\mathrm{n}(\mathrm{N}=61)$ & $\begin{array}{c}\text { Median OS } \\
\text { (months) }\end{array}$ & \multicolumn{2}{|c|}{ Univariate analysis } & \multicolumn{2}{|c|}{ Multivariate analysis } \\
\hline \multicolumn{7}{|l|}{ Hook1 } \\
\hline- & 26 & 34 & 0.539 & 0.463 & $0.781(0.352-1.737)$ & 0.545 \\
\hline+ & 35 & 25 & & & & \\
\hline+ & 37 & 24 & & & & \\
\hline \multicolumn{7}{|l|}{ SHP2 and Hook1 } \\
\hline (-) Both & 14 & 68 & 3.591 & 0.058 & $1.285(0.305-5.408)$ & 0.733 \\
\hline Positive in one or both & 47 & 25 & & & & \\
\hline
\end{tabular}

SHP2, Src homology region 2-containing protein tyrosine phosphatase 2; NSCLC, non-small cell lung cancer.

Table 5 Correlation between the PFS and the expressions of SHP2 or/and Hook1 in NSCLC patients

\begin{tabular}{|c|c|c|c|c|c|c|}
\hline & $n(N=55)$ & $\begin{array}{l}\text { Median PFS } \\
\text { (months) }\end{array}$ & \multicolumn{2}{|c|}{ Univariate analysis } & \multicolumn{2}{|c|}{ Multivariate analysis } \\
\hline \multicolumn{7}{|l|}{ Hook1 } \\
\hline- & 23 & 12 & 1.521 & 0.217 & $1.167(0.523-2.605)$ & 0.706 \\
\hline+ & 32 & 8 & & & & \\
\hline- & 20 & 12 & 2.076 & 0.15 & $1.833(0.729-4.611)$ & 0.198 \\
\hline+ & 35 & 9 & & & & \\
\hline \multicolumn{7}{|l|}{ SHP2 and Hook1 } \\
\hline$(-)$ Both & 12 & 12 & 1.597 & 0.206 & 1.297 (0.370-4.542) & 0.684 \\
\hline
\end{tabular}

SHP2, Src homology region 2-containing protein tyrosine phosphatase 2; NSCLC, non-small cell lung cancer.

Table 6 Effect of Hook1 expression on the OS and PFS in SHP2 positive NSCLC patients

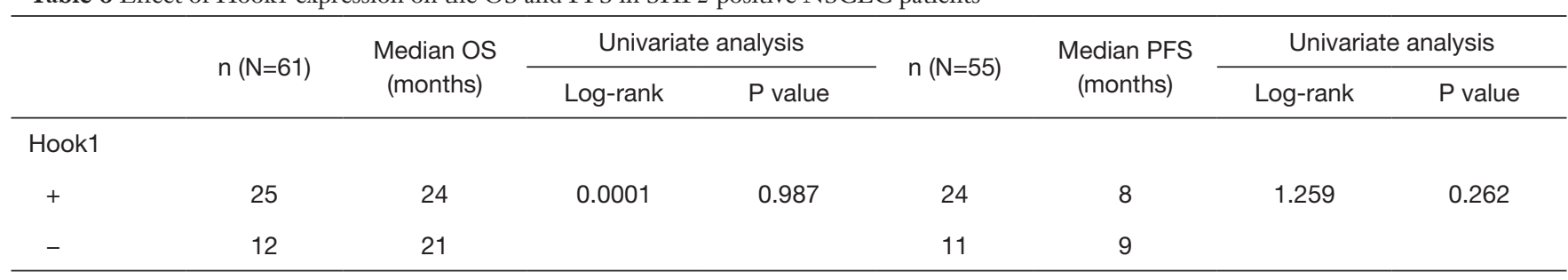

PFS, progression-free survival; SHP2, Src homology region 2-containing protein tyrosine phosphatase 2; NSCLC, non-small cell lung cancer.

In the present study, a total of 61 patients with NSCLC receiving gemcitabine plus carboplatin chemotherapy were evaluated. Immunohistochemical staining was conducted to detect the protein expression of SHP2 and Hook1. In tumor tissue specimens, the expression rates of SHP2 and Hook 1 proteins were $60.7 \%$ and $57.4 \%$, respectively. The total expression rate for SHP2 and Hook1 was $71.4 \%$. A significant correlation between the positive expression 
of SHP2 and the positive expression of Hook1 was observed $(\mathrm{P}=0.046, \mathrm{r}=0.256)$. The positive rate of Hook1 protein expression varied in different pathological types (histology), adenocarcinoma was higher than squamous cell carcinoma $(73.5 \%$ vs. $31.2 \%, \mathrm{P}=0.013)$. While in different clinical stages (Stage), the late stage patients (IIIb-IV phase) expressed more Hook1 protein than that of the early (I-IIIa) stage patients $(75 \%$ vs. $48.8 \%$, $\mathrm{P}=0.05)$. Since Hook1 not only binds to SHP2, but also affects the subcellular localization of SHP2 and inhibits its enzyme activity, the increased Hook1 protein expression rate in late NSCLC may suppress the catalytic activity of SHP2. The survival rate of patients with negative SHP2 protein expression was higher than that of patients with positive SHP2 protein expression [median overall survival (OS) 68 vs. 24 months, $\mathrm{P}=0.003]$. However, there was no significant correlation between the expression of Hook1 and the survival time of patients $(\mathrm{P}>0.05)$. The comparison of tumor tissues expressing both SHP2 and Hook1 with tumor tissues expressing either SHP2 or Hook1 showed median OSs of 68 versus 25 months $(\mathrm{P}=0.058)$ respectively, indicating a significant impact of SHP2 and Hook1 proteins on NSCLC patient survival. We further analysed the effect of Hook1 expression on OS and PFS in SHP2 positive patients. The results showed that there was no significant correlation between Hook1 expression level and OS and PFS in SHP2 positive patients $(\mathrm{P}>0.05)$. The results indicate that the regulation of tyrosine phosphatase SHP2 activity affects the development of lung cancer. In addition to the anchoring protein Hook1, there may be other biologically active molecules or signaling pathways to be discovered by further basic or clinical large sample studies. Cox multivariate regression analysis showed that SHP2 expression in tumor tissue (HR: $4.520,95 \%$ CI: 1.470-14.021, P=0.009) was an independent indicator for overall survival. No significant correlation between the protein expression of SHP2 or Hook1 and NSCLC disease progression was observed $(\mathrm{P}>0.05)$. It is noteworthy that in addition to NSCLC, SHP2 could act as a tumor suppressor in hepatocellular carcinoma, thyroid carcinoma, colon cancer and carcinogenesis because of its downregulation of inflammatory signalling, but Hook1 was negatively associated with the invasiveness of tumor cells, and the regulatory relationship between SHP2 and Hook1 may differ based on the type or stage of the tumor (24,33-35).

In conclusion, the present study indicates that NSCLC patients with negative SHP2 expression in tumor tissue could benefit from gemcitabine plus carboplatin chemotherapy. It is suggested that SHP2 may be a favourable indicator of prognosis in NSCLC. However, further study will be needed to confirm the prognostic value of SHP2 and Hook1.

\section{Acknowledgments}

We thank all our collaborators who helped with this study. Funding: This study was supported by grants of the National Science Foundation of China (No. 81673512, 81573502), the Medical Science Research Fund Scheme of Zhejiang Province (No. 2017KY332), and Zhejiang provincial science and Technology Department, public technology research, social development project (LGF18H310002).

\section{Footnote}

Reporting Checklist: The authors have completed the REMARK reporting checklist. Available at http://dx.doi. org/10.21037/apm-20-430

Data Sharing Statement: Available at http://dx.doi. org/10.21037/apm-20-430

Conflicts of Interest: All authors have completed the ICMJE uniform disclosure form (available at http://dx.doi. org/10.21037/apm-20-430). The authors have no conflicts of interest to declare.

Ethical Statement: The authors are accountable for all aspects of the work in ensuring that questions related to the accuracy or integrity of any part of the work are appropriately investigated and resolved. The study was conducted in accordance with the Declaration of Helsinki (as revised in 2013). The study was approved by the Research Ethics Committee of the First Affiliated Hospital, School of Medicine, Zhejiang University (2016125) and informed consent was taken from all the patients.

Open Access Statement: This is an Open Access article distributed in accordance with the Creative Commons Attribution-NonCommercial-NoDerivs 4.0 International License (CC BY-NC-ND 4.0), which permits the noncommercial replication and distribution of the article with the strict proviso that no changes or edits are made and the original work is properly cited (including links to both the formal publication through the relevant DOI and the license). See: https://creativecommons.org/licenses/by-nc-nd/4.0/. 


\section{References}

1. Morodomi Y, Takenoyama M, Inamasu E, et al. Non-small cell lung cancer patients with EML4-ALK fusion gene are insensitive to cytotoxic chemotherapy. Anticancer Res 2014;34:3825-30.

2. Tang XL, Yan L, Zhu L, Jiao DM, Chen J, Chen QY. Salvianolic acid A reverses cisplatin resistance in lung cancer A549 cells by targeting c-met and attenuating Akt/ mTOR pathway. J Pharmacol Sci 2017;135:1-7.

3. Zhang Q, Zhai S, Li L, et al. P-glycoprotein-evading antitumor activity of a novel tubulin and HSP90 dual inhibitor in a non-small-cell lung cancer model. J Pharmacol Sci 2014;126:66-76.

4. Wang RR, Liu WS, Zhou L, Ma Y, et al. Probing the acting mode and advantages of RMC-4550 as an Src-homology 2 domain-containing protein tyrosine phosphatase (SHP2) inhibitor at molecular level through molecular docking and molecular dynamics. J Biomol Struct Dyn 2020;38:1525-38.

5. Ahmed TA, Adamopoulos C, Karoulia Z, et al. SHP2 Drives Adaptive Resistance to ERK Signaling Inhibition in Molecularly Defined Subsets of ERK-Dependent Tumors. Cell Rep 2019;26:65-78.e5.

6. Rikova K, Guo A, Zeng Q, et al. Global survey of phosphotyrosine signaling identifies oncogenic kinases in lung cancer. Cell 2007;131:1190-203.

7. Pawson T, Nash P. Assembly of cell regulatory systems through protein interaction domains. Science 2003;300:445-52.

8. Tonks NK. Protein tyrosine phosphatases: from genes, to function, to disease. Nat Rev Mol Cell Biol 2006;7:833-46.

9. First-Line Crizotinib versus Chemotherapy in ALKPositive Lung Cancer. N Engl J Med 2015;373:1582.

10. Abbasi M, Gupta V, Chitranshi N, et al. Regulation of Brain-Derived Neurotrophic Factor and Growth Factor Signaling Pathways by Tyrosine Phosphatase Shp2 in the Retina: A Brief Review. Front Cell Neurosci 2018;12:85.

11. Tajan M, de Rocca SA, Valet P, Edouard T, Yart A. SHP2 sails from physiology to pathology. Eur J Med Genet 2015;58:509-25.

12. Zhang J, Zhang F, Niu R. Functions of Shp2 in cancer. J Cell Mol Med 2015;19:2075-83.

13. Neel BG, Gu H, Pao L. The 'Shp'ing news: SH2 domaincontaining tyrosine phosphatases in cell signaling. Trends Biochem Sci 2003;28:284-93.

14. Li S, Hsu DD, Wang H, Feng GS. Dual faces of SH2containing protein-tyrosine phosphatase Shp2/PTPN11 in tumorigenesis. Front Med 2012;6:275-9.

15. Bard-Chapeau EA, Li S, Ding J, et al. Ptpn11/Shp2 acts as a tumor suppressor in hepatocellular carcinogenesis. Cancer Cell 2011;19:629-39.

16. Ke Y, Zhang EE, Hagihara K, et al. Deletion of Shp2 in the brain leads to defective proliferation and differentiation in neural stem cells and early postnatal lethality. Mol Cell Biol 2007;27:6706-17.

17. Ke Y, Lesperance J, Zhang EE, et al. Conditional deletion of Shp2 in the mammary gland leads to impaired lobuloalveolar outgrowth and attenuated Stat 5 activation. J Biol Chem 2006;281:34374-80.

18. Won KJ, Lee HM, Lee CK, et al. Protein tyrosine phosphatase SHP-2 is positively involved in plateletderived growth factor-signaling in vascular neointima formation via the reactive oxygen species-related pathway. J Pharmacol Sci 2011;115:164-75.

19. Lauriol J, Jaffre F, Kontaridis MI. The role of the protein tyrosine phosphatase SHP2 in cardiac development and disease. Semin Cell Dev Biol 2015;37:73-81.

20. Ubersax JA, Ferrell JJ. Mechanisms of specificity in protein phosphorylation. Nat Rev Mol Cell Biol 2007;8:530-41.

21. Chen L, Du-Cuny L, Moses S, et al. Novel inhibitors induce large conformational changes of GAB1 pleckstrin homology domain and kill breast cancer cells. PLoS Comput Biol 2015;11:e1004021.

22. Kan C, Yang F, Wang S. SHP2-Mediated Signal Networks in Stem Cell Homeostasis and Dysfunction. Stem Cells Int 2018;2018:8351374.

23. Li S, Wang L, Zhao Q, et al. SHP2 positively regulates TGFbeta1-induced epithelial-mesenchymal transition modulated by its novel interacting protein Hook1. J Biol Chem 2014;289:34152-60.

24. Cao J, Huang YQ, Jiao-Sun, Lan XB, Ge MH. Clinicopathological and prognostic significance of SHP2 and Hook1 expression in patients with thyroid carcinoma. Hum Pathol 2018;81:105-112.

25. Fu MM, Holzbaur EL. Integrated regulation of motordriven organelle transport by scaffolding proteins. Trends Cell Biol 2014;24:564-74.

26. Maldonado-Báez L, Cole NB, Kramer H, Donaldson JG. Microtubule-dependent endosomal sorting of clathrinindependent cargo by Hook1. J Cell Biol 2013;201:233-47.

27. Bentires-Alj M, Paez JG, David FS, et al. Activating mutations of the noonan syndrome-associated SHP2/ PTPN11 gene in human solid tumors and adult acute myelogenous leukemia. Cancer Res 2004;64:8816-20. 
28. Correction: The Tyrosine Phosphatase Shp2 Interacts with NPM-ALK and Regulates Anaplastic Lymphoma Cell Growth and Migration. Cancer Res 2016;76:1669.

29. Voena C, Conte C, Ambrogio C, et al. The tyrosine phosphatase Shp2 interacts with NPM-ALK and regulates anaplastic lymphoma cell growth and migration. Cancer Res 2007;67:4278-86.

30. Tang C, Luo D, Yang H, et al. Expression of SHP2 and related markers in non-small cell lung cancer: a tissue microarray study of 80 cases. Appl Immunohistochem Mol Morphol 2013;21:386-94.

31. Schneeberger VE, Ren Y, Luetteke N, et al. Inhibition of Shp2 suppresses mutant EGFR-induced lung tumors in transgenic mouse model of lung adenocarcinoma.

Cite this article as: Yang $\mathrm{H}$, He L, Zhang Y, Li Y, Huang X, Li Y, Lou Y, Wang L. The clinicopathological and prognostic implications of Tyrosine phosphatase SHP2 and ankyrin Hook1 gene expression in non-small cell lung cancer patients treated with gemcitabine plus platinum as first-line chemotherapy. Ann Palliat Med 2020;9(5):2943-2952. doi: 10.21037/apm-20-430
Oncotarget 2015;6:6191-202.

32. He LJ, Cheng HQ, Ke YH et al. Research progress in the role of protein tyrosine phosphatase SHP2 in lung cancer. Chin J Pharmacol Toxicol 2016;1:82-6.

33. Sun $X$, Zhang Q, Chen W, et al. Hook1 inhibits malignancy and epithelial-mesenchymal transition in hepatocellular carcinoma. Tumour Biol 2017;39:1010428317711098.

34. Yang W, Wang J, Moore DC, et al. Ptpn 11 deletion in a novel progenitor causes metachondromatosis by inducing hedgehog signalling. Nature 2013;499:491-5.

35. Cai P, Guo W, Yuan H, et al. Expression and clinical significance of tyrosine phosphatase SHP-2 in colon cancer. Biomed Pharmacother 2014;68:285-90. 